\title{
Modeling U.S. Manufacturing Competitiveness
}

\author{
Eric B. Dent, University of North Carolina Pembroke \\ Robert Hughes, University of North Carolina Pembroke
}

\begin{abstract}
Few issues are discussed as frequently by American politicians as jobs, and particularly the loss of jobs, ostensibly to cheaper labor markets. The underlying reasons why some firms depart American soil and others do not, however, are not completely understood. The purpose of this study is to propose a model for determining what successful manufacturers are doing to remain competitive and, consequently, not moving to other countries unnecessarily.

There is no extant model that effectively differentiates what successful manufacturers are doing compared with unsuccessful (i.e., job-cutting or factory-closing) ones. To develop this conceptual model, we have conducted interviews with manufacturers in our region (one of the poorest in the country and one that has lost over 10,000 manufacturing jobs and 52 of 141 manufacturing plants between 1993-2003). We have also completed an exploratory content analysis of the literature on this subject. From this analysis, we have developed a model that will be described here. The model consists of five primary differentiators: (1) the flow of vital information, (2) the human factor (leadership, teamwork, etc.), (3) issues of cost and efficiency, (4) integration of information technology, and (5) cooperative methodologies.
\end{abstract}

\section{Background of the Proposed Effort and Research Question}

According to the National Association of Manufacturers, over 3 million American manufacturing jobs were lost from 1998 to 2003. Since manufacturing currently accounts for more than 20 percent of GDP, the problem in the decline of the manufacturing industry threatens the entire U.S. economy (Eisen, 2003). Every million dollars in manufacturing sales supports eight jobs in manufacturing and six in other allied sectors. Debates concerning the overall and long term effects of outsourcing not withstanding, it is clear that substantial numbers of manufacturing plants have closed with a heart-breaking toll on millions of Americans who have been unable to find employment at comparable levels. Although certain economic cycles are inevitable and beneficial to the whole economy, it is also the case that if companies can eliminate inefficiencies and other suboptimalities in their organizations, it may be that not as many jobs need to be relocated.

Although most companies have addressed factors resulting in outsourcing, some manufacturing plants have been able to stay open, remain competitive, and even increase their employment levels in a post-NAFTA society. This study is an example of positive organizational scholarship, looking at successes instead of failures. We analyzed in detail over 100 articles and were unable to find any model explaining what successful companies are doing that have differentiated themselves from those that have moved overseas. A number of anecdotes exist, but no systematic research has been done from this perspective.

The purpose of this study is to propose a model for determining what successful manufacturers are doing to remain competitive and, consequently, not moving to other countries unnecessarily. In other words, what distinguishes "successful stayers"-those that have retained 
the majority of their production operations in the United States-from "leavers?" Although there is disagreement about what level of manufacturing needs to take place within a single country, all recognize that national security issues become a factor at a certain level. A level of manufacturing in a country is also economically important because manufacturing's varied jobs and careers averaged $\$ 54,000$ in salary in 2000, twenty percent higher than the average of all American workers. Also, 83 percent of manufacturing employees receive health benefits from their employers, which are more than any other sector except government (National Association of Manufacturers, 2001).

\section{Literature Review, Theory, and Testable Hypotheses}

We conducted a qualitative narrative analysis (Miles \& Huberman, 1984) to produce emergent categories rather than predetermined ones. This step resulted in the emergence (Boyatzis, 1998) of five thematic categories that were the most common in the literature on manufacturing competitiveness. Thematic categories surfaced from the data as the researchers used an inductive process (Strauss \& Corbin, 1998) to immerse themselves in the data, discuss and debate among themselves, and be open for patterns and themes to come in to view. Category creation is vital because "categories are the cornerstones of developing theory in that they produce the means by which the theory can be integrated" (Strauss \& Corbin, 1998, p. 7). Solid theory can develop through the interplay of concepts, categories, and propositions in an iterative dance. The decision factors for including the categories were based on the researchers' persuasiveness, plausibility, coherence, and pragmatic applicability to theory development (Huberman \& Miles, 2002). The resultant categories hold the most promise for advancing and/or developing theory in the areas of manufacturing competitiveness.

The model consists of five primary differentiators - the flow of vital information, the human factor (leadership, teamwork, etc.), issues of cost and efficiency, integration of information technology, and cooperative methodologies.

\section{Flow of Vital Information}

Information sharing and creative collaboration between individual employees and groups or teams of employees is a pervasive topic in current literature on the subject of manufacturing competitiveness. Implementation of automated manufacturing systems has reduced the numbers of employees required to operate and monitor production lines. However, these same systems require workers with enhanced skills to perform these tasks. These more highly skilled employees need more information to perform their jobs, causing the flow of information and knowledge through organizations to take on far greater importance.

| This phenomenon is well illustrated by the Caterpillar Corporation_whose top managers consider its competitive advantage to be the experience and expertise of its technical employees. However, this knowledge, experience and expertise has upper limits on their collective value to the company if these valuable assets remain confined to individuals and are not shared with others. To reach its value potential, this vast amount of accumulated knowledge must be gathered, synthesized and disseminated throughout the organization. . Caterpillar employs a concept termed Community of Practice $(\mathrm{CoP})$ to facilitate the sharing of information within 
throughout the organization. A CoP is a group of people held together by common interests and problems (Luthans \& Youssef, 2004). The same people hold the intangible, tacit knowledge and experiences of the organization (Dhanaraj, Lyles, Steensma, \& Tihanyi, 2004). Since Caterpillar has 100 locations in 20 different countries and employs approximately 60,000 workers, Caterpillar has harnessed the power of the Internet to facilitate information sharing. The Caterpillar Knowledge Network is a corporate Intranet that enables efficient information sharing. It is composed of "virtual communities" many of which were formed on the initiative of employees. Trust has been built among and between "community" members and management, and is the key to successful implementation and use of such information sharing vehicles.

Knowledge management is also critical to manufacturing competitiveness. The consensus of various authors is that the most successful knowledge management systems are non-intrusive, intuitive and do not remove focus from the purpose of the organization (Beckett \& Hyland, 2002).

\section{Hypothesis 1: Successful manufacturers will have evolved to establishing jobs that require greater skill and more information to perform.}

\section{The Human Factor}

The common theme in the literature that we label "the human factor" encompasses aspects of interpersonal interaction such as plant leadership, teamwork, and "presenteeism." In one of the largest and most comprehensive recent studies of organizations, (Collins 2001) discovered that the most effective leaders (Level 5) have a paradoxical combination of personal humility and professional will. This work starkly contrasts the common perception that the charismatic, visible leader achieves the best organizational performance.

Teamwork continues to be a dominant theme in the literature, but there are some new twists. As noted above, the concept of communities of practice is redefining the notion of the team membership of an employee (Luthans \& Youssef, 2004). Moreover, what constitutes a team contribution must also now be seen in terms of assets such as social capital (Yli-Renko, Autio, \& Sapienza, 2001; Cohen \& Prusak, 2001). Terms such as empowerment and trust are much more readily found in the literature than they would have been a decade ago. Employees will be much more motivated to do a good job and operate efficiently as individuals if they feel that they are making a meaningful contribution to a group goal. Support for appropriate levels of autonomy, decision-making responsibility of self-managed, empowered teams and two way trust relationship with management are key to creating a workplace where individuals will feel a high measure of fulfillment in their work (Fry, 2003).

Finally, a relatively new concept warrants exploration in our study. "Presenteeism" occurs when employees are present for duty and ostensibly attempt to function effectively, but do not perform at their full potential due to illness or other medical conditions (Hemp, 2004). This loss of productivity can be very costly, indeed it may exceed costs associated with health benefits, disability, and absenteeism. Research in this emerging area is built on the premise that employees in question do not take their jobs lightly and want to do a good job, but are adversely affected by various illnesses. Costs, while high, are difficult to accurately quantify due to the 
ripple affect that one person's decrease in productivity can have on a larger group. Companies can learn to manage this phenomenon by investing in wellness programs and encouraging and enabling employees to better manage both chronic and short-term health issues (Hemp, 2004).

\title{
Hypothesis 2a: Successful manufacturers are characterized by \\ plant managers that display both personal humility and \\ professional will.
}

\begin{abstract}
Hypothesis 2b: Employees in successful manufacturers will identify themselves as members of more than one team, and display high levels of trust.
\end{abstract}

Hypothesis 2c: Successful manufacturers have programs in place to reduce "presenteeism."

\section{Issues of Cost and Efficiency}

The general disparity in production costs between American manufacturers and their foreign counterparts is widely acknowledged. A textile worker in China, for example, earns about $\$ .60$ cents an hour, while a similar worker in the United States can make as much as \$18. per hour. Extant literature suggests that mitigating this circumstance requires new techniques and practices to increase efficiency. These included agile and lean manufacturing, as well as integrated information technology and computer control systems.

American firms are attempting to remain competitive by emphasizing higher end products or niche markets better served by high technology manufacturing with highly skilled labor as opposed to cheap mass-production. The focus is on quality and the ability to deliver goods quickly, as opposed to low price (Kurlantzick, 2003). Companies are also taking a hard look at manufacturing practices and are attempting to remove wasteful practices wherever possible. For example, a process oriented manufacturing industry doing business internationally developed the objective to reduce the amount of scrap/waste by fifty percent within three years. The company's vision was not to think of scrap as a part of the production process but as a controllable expense like any other business cost. The firm reached its goal of scrap savings in excess of 15 million dollars and the firm's overall competitiveness improved causing revenues and net income to increase over a three-year period (Vorkurka \& Davis, 1996).

Efficiency in manufacturing is also a key focus in the current literature. Agile and lean manufacturing are concepts that are well represented in discussions of manufacturing competitiveness. Agile manufacturing (AM) is characterized by the ability to react quickly and effectively to changing market conditions. AM includes customer integrated processes, decision making at functional knowledge points, flexible manufacturing, and easy access to accumulated knowledge, integrated data and modular production facilities. AM is driven by the need to respond quickly to customer demands and changing requirements. Six key strategies and technologies constitute the framework for achieving AM: (1) partnership formation and supply chain development, (2) the use of IT in manufacturing, (3) enterprise integration and management with the help of advanced IT, (4) the use of virtual reality tools and techniques, 
(5) application of advanced manufacturing concepts, and (6) a global manufacturing/service perspective in physically distributed manufacturing environments (Gunasekaran \& Yusuf, 2002).

Lean manufacturing, a concept developed at Toyota, is an enhancement of mass production. Continuous quality improvement, reduction of inventory and work-in-progress, and the reduction or elimination of waste of any kind are the hallmarks of lean manufacturing practices (Sahin, 2000). Mass customization, an ostensible oxymoron, is a method of achieving efficiency based on time demands and the ability to meet rapidly changing customer demands. Technology and management methods are used to offer a variety of products and customized products through flexibility of manufacturing resources and quick responsiveness to demand. Mass customization demands a dynamic organization composed of relatively autonomous operating units. Modules devoted to a specific task or process interact with other modules in varying sequences for every individual product demanded by customers (Sahin, 2000). Flexible manufacturing cells give a manufacturer a way to work on many tasks simultaneously, thus gaining a time advantage. Each cell performs a specialty function while other cells are performing their own functions at the same time (Charkiewicz, 2004).

\section{Hypothesis 3: Successful manufacturers employ techniques such as agile manufacturing or mass customization to increase productivity.}

\section{Integration of Information Technology}

The integration of advanced information technology into the manufacturing process is of paramount importance in achieving a high degree of competitiveness. Automated systems involve some sort of computer-based control and monitoring. Redundancy and unnecessary paper work can often be avoided by the careful implementation of advanced information technology. Computer networks and access to the Internet are key features that enable information sharing throughout organizations. The timely dissemination of relevant information is critical in a world that is increasingly focused on the assembly, assessment, and use of knowledge. The ability to make informed, critical decisions rapidly enables advanced manufacturing techniques to succeed. This ability is highly dependent on rapid access to needed information. Examples of information could include: inventory levels, machine status, or realtime sales figures. Enterprise Resource Planning (ERP) software and systems allow this kind of rapid access to information. A good example of the integration of IT into manufacturing is the concept of a Total Manufacturing Information System (TMIS) based on the total integration of manufacturing and business information. Research supports the idea that all functions operating together as a system through adequate flow of information among all functions in an organization is much more efficient than even sub-optimization at the individual function level (Lee, 2003).

Multi-disciplinary teamwork is critical in the production of TMIS systems. Everyone has something to add. Contribution across the board is important to getting the system right from the beginning and being able to immediately reap benefits. Total buy-in, created in part by involvement of employees from across the organization, increases the usefulness of the system (Lee, 2003). 
SAP is another example of an ERP system that successful companies are employing. Companies have achieved great benefits with these systems when they have seen them not as stand alone technology, but integrated with a company's strategy, organization, and culture (HsiuJu \& Chwen, 2004).

\section{Hypothesis 4: Successful manufacturers are systematically increasing the technology used in each position in the organization to increase productivity.}

\section{Cooperative Methodologies}

Inter-firm clustering and partnering refers to the cooperation between related or complementary manufacturing firms to enhance the flow and sharing of information and knowledge and the use of skills and equipment to cooperatively manufacture a finished product. Each individual plant concentrates on the part of the process that it is most well equipped to do (Davies, 2001). Clusters, the flow of knowledge between clusters, and how the flow affects competitive advantage is the subject of much present research in the areas of international strategy and competitiveness. Researchers in the field of economic geography are also interested in the notion of industrial clusters. Regional clusters can be defined as a geographically proximate or otherwise connected, group of companies and associated institutions in a particular field, linked by common or complementary factors (Henry, Jenkins, Pinch \& Tallman, 2004). Success of clusters can be determined by forces both inside and outside the cluster, such as government supplied infrastructure support or the internal flow of knowledge within the cluster.

The speed of current global communications and information transfer has made geography less important to the idea of clusters. Knowledge that flows along established lines of communication within clusters can be ascribed to two categories: (1) component knowledge and (2) architectural knowledge. Component knowledge refers to the technology of the industry and includes specific knowledge resources and collective skills. The more technical a piece of component knowledge is the faster and more accurately it will be disseminated in the cluster. Architectural knowledge refers to the organization of the cluster and structure and routines for integrating component knowledge into patterns of productive use and for developing new knowledge (Henry, Jenkins, Pinch \& Tallman, 2004). Understanding networks is the key to understanding clusters. Network linkages either occur between firms performing similar activities in the same sector to improve economies of scale or between firms that perform complementary activities. Trust is paramount in these interactions (Davies, 2001).

Hypothesis 5: Successful manufacturers will have more partnership institutional arrangements and will be more interdependent with these partners. 


\section{Synthesis}

The relationships among the hypotheses should be noted. For example, when technology is utilized in production (H3), it is likely that greater skills and access to information will be required for workers to fulfill job requirements. In a broad sense, it is anticipated that organizations emphasizing such factors as skills, effective leadership, teamwork, trust, productivity, technology, and effective partnerships will be more likely to forego production outsourcing (i.e., stay instead of leave) than their counterparts that do not embody such characteristics. Table 1 summarizes the hypotheses to be addressed in the study. Figure 1 provides an illustration, emphasizing the prospective relationships among key variables.

\section{Table 1: Summary of Hypotheses}

\begin{tabular}{|c|l|c|c|}
\hline Hypothesis & \multicolumn{1}{|c|}{ Variable } & Stayers & Leavers \\
\hline H1 & Worker skills and information required to perform job & High & Low \\
\hline H2a & $\begin{array}{l}\text { Ability of plant managers to embody both humility and } \\
\text { strong personal will }\end{array}$ & High & Low \\
\hline H2b & Worker teamwork and trust & High & Low \\
\hline H2c & Efforts to minimize presenteeism & High & Low \\
\hline H3 & Worker productivity & High & Low \\
\hline H4 & Utilization of technology & High & Low \\
\hline H5 & Organizational partnerships and interdependence & High & Low \\
\hline
\end{tabular}

Figure 1: Factors Influencing Decision to Stay or Leave

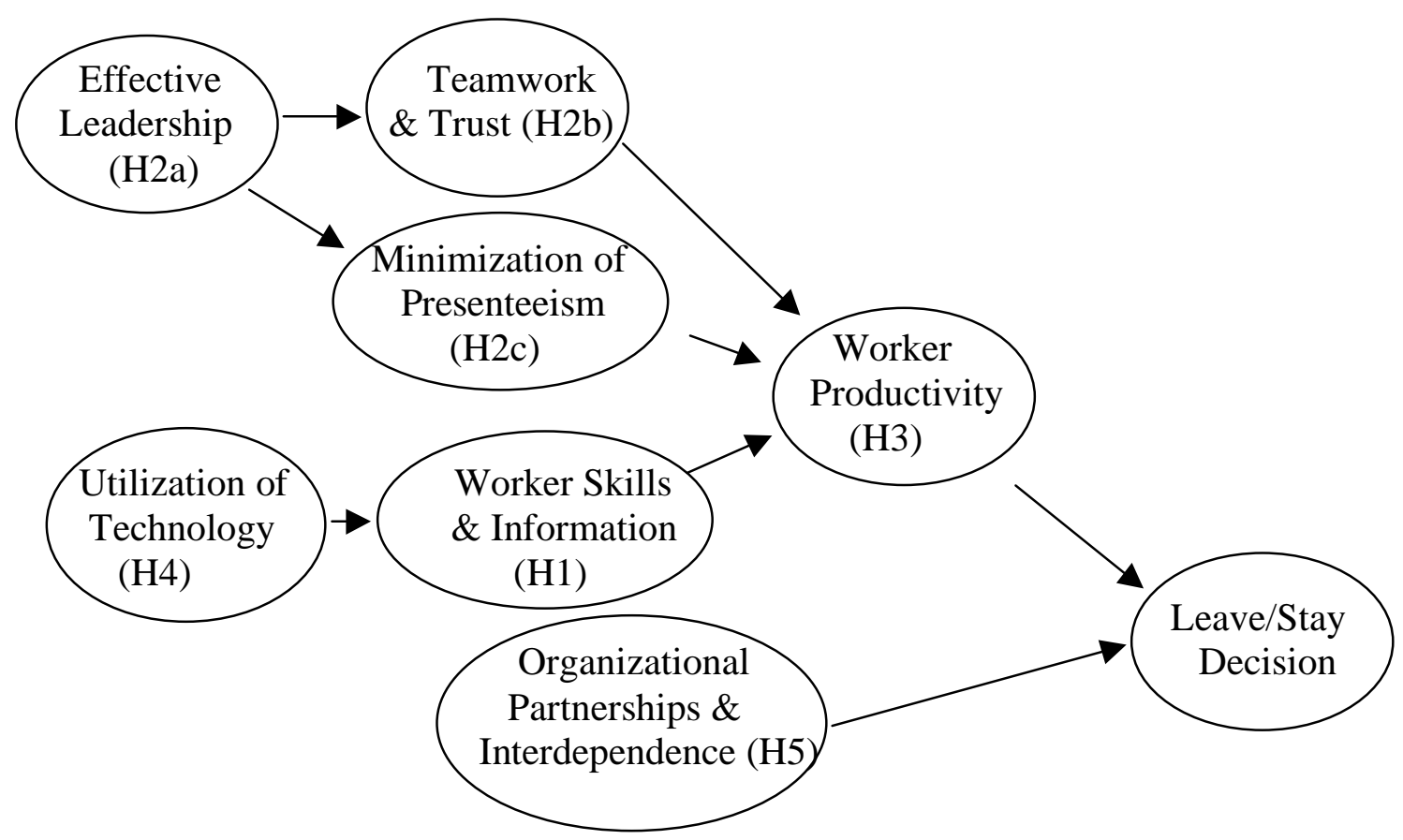




\section{Select Southeastern North Carolina Companies: Profiles in Success}

While manufacturing in America is suffering an extended period of job loss and plant closings, there are signs of recovery and even of success. Examples of two such firmsCampbell Soup and Unilever-are discussed briefly herein. These examples lend credence to the notion that viable alternatives to outsourcing production exist, even in highly competitive industries.

\section{Campbell Soup, Maxton, North Carolina}

Fred George, plant manager at Campbell notes that the firm is spending $\$ 50$ million to install two new production lines devoted entirely to "pop-top" type containers. Market research has shown that convenience is a primary concern to American consumers.

Campbell recognizes the value of its human resources and the strong relationship that well trained workers have on productivity and, therefore, competitiveness. Each employee at the plant participates in at least twenty-five hours of training per year. Many aspects of line operations at the plant are automated, requiring highly skilled operators to monitor the systems. There is also an integrated computer control and inventory system in operation at the plant. This system monitors inventory levels of both finished product and raw materials and triggers the ordering process for additional raw materials inventory.

In short, Campbell has recognized that its employees are an integral component of its competitive strategy. Campbell has also recognized the benefits of automated manufacturing systems and integrated software and computer systems. Campbell has implemented a PLC Manufacturing Control System, including a Recipe Management System. Information is entered via a control panel. This starts the process of ingredients moving toward the production area. The significance is noteworthy when one considers that Campbell processes 150 tons of vegetables a day to produce six million cans of soup per day.

\section{Unilever, Raeford, North Carolina}

Unilever is a publicly held company that employs 234,000 people in 100 countries worldwide. Unilever's Raeford Plant consists of two business units, deodorants and personal wash liquids. Unilever is investing heavily in equipment and their most valuable resources, the employees or the teammates. Unilever is investing millions in the lines to make them more automated. For example, R1, the plant's oldest deodorant line, has nine teammates producing about 120 pieces a minute, while R4, the plant's newest deodorant line, has six teammates producing about 205 pieces a minute. Automation reduces the size of the work force, but improves competitiveness.

The workforce at Unilever-Raeford is guided by a "skill block" promotion system that permits each employee to advance to different levels in their current job. The system has five blocks with required qualifications for the employee to achieve in order to advance to the next block and receive a pay raise. An employee can remain at a particular block for a maximum of eighteen months, but must function within a block for a minimum of six months before they are 
able to advance to the next level. An employee must make it to skill block two, however, in order to remain in good standing, however. Skill blocks three and four have different certification and degrees to achieve in order to reach these levels. This new system enables Unilever to retain high performing employees and remain competitive.

The Raeford Plant credits an activity call TPM (Total Productive Manufacturing), defined as a daily management strategy to achieve business goals while also creating a safe and efficient work environment, for maintaining competitiveness. Inherent in the notion of TPM is the importance of an effective corporate culture, the inclusion of all departments in TPM activities with the goal of eliminating losses, and the involvement of the entire workforce in zero-loss activities accomplished through overlapping small group activities.

TPM has allowed for important efficiency improvements in the plant. OEE, Overall Equipment Efficiency, is a measure of the speed that the manufacturing equipment attains. In 2003, Raeford's OEE, fell below 50 percent. Today, the OEE is in the 55-56 percent range.

\section{Conclusions and Introduction of Conceptual Model}

There are many crucial challenges facing American manufacturing in today's global, highly competitive economy. Several "stayers" have demonstrated thus far that these challenges can be met and U.S. manufacturers can successfully compete both at home and with manufacturing companies abroad.

Meeting the needs of employees post-hire is central to making employees feel viable, included, necessary and committed to their work. Distributed decision making, empowering selfdirected teams, and seeking input from the rank and file will help meet the higher level needs of employees (Fry, 2003). With today's work schedules, employees spend the majority of their waking hours at work. It is not surprising that their sense of community and of belonging is tied to their work environment (Fry, 2003).

Automation of production and integration of advanced IT and computerized control systems is extremely important. The flow of information, control of machinery, real-time access to critical data, and the sharing of knowledge all require advanced systems that need input from every level of the organization. Failure to integrate all available, relevant technology into the manufacturing process stifles creativity and efficiency. The cost of implementing these strategies should be seen as a necessary investment in the future viability of any manufacturing company.

The ability to successfully compete in a global economy is contingent upon a process of continuous improvement through training, knowledge sharing, and close attention to the quality of manufactured goods. Local firms engaging in similar or complementary manufacturing processes can pool their knowledge and experience to improve their processes and look for ways to cooperate and grow. The importance of employee training cannot be overstated. As the technological complexity of manufacturing equipment rises, employee skills must rise as well. 


\section{Critique of the Model}

Manufacturing firms have been studied for more than a century yet no one has developed what we offer here: a comprehensive model and blueprint for helping manufacturers remain competitive. Management history can shed light on the limitations of previous models. Frederick Taylor was among the first to focus on increasing the efficiency of the assembly process. Studies such as Hawthorne and Harwood (Coch \& French, 1948) focused on the human element. Systemic approaches began in the 1950's \& 1960's, but this was the same era in which corporations began limiting access with the "black box." Today, we have the tools to take an even "deeper" systems approach than would have been conceived in the 1960's. By including tacit knowledge and qualitative methods to extract the most critical information about, for example, how information is diffused through the organization and how social capital formation occurs, this model pushes the envelope of research and scholarship.

Use of this model will provide a blueprint for organizational change in manufacturing. Perhaps, the most frequently used model for organizational change today is the work of (Kotter, 1996). His prescriptions, however, are generic, including steps such as "establish a sense of urgency" and "empower employees for broad-based action." The proposed model, on the other hand, will result in very specific guidelines. Some possible outcomes could be "ensure that all employees can perform at least three different tasks within the plant" or "put feedback process in place so that each person knows, as soon as possible, the outcome and quality of his or her work."

A triangulated research approach emphasizing both quantitative and qualitative methods is germane. In contrast, the approaches adopted in most extant studies have been either predominantly quantitative or qualitative. Quantitative studies tend to emphasize economic factors such as labor and other production costs, typically assessing the success or failure of a prospective outsourcing decision vis-à-vis short-term financial ramifications. On the other hand, qualitative approaches tend to be limited to a single organization and or a single time frame. Both quantitative and qualitative approaches have provided insight into the phenomena of production outsourcing, but neither approach has offered a comprehensive perspective. Data envelopment analysis (DEA) represents an example. DEA will be used to analyze survey data within each organization. DEA is a linear-programming based technique that seeks to identify "best practice" information from a set of data. While traditional parametric analyses (e.g., regression) can impose artificial relationships or functional forms on a data set, DEA starts from within the data itself, measuring relative performance by estimating an empirical function (frontier) that represents the most efficiently performing observations. "Efficient" observations are defined as those which reap the highest values of outputs/benefits for their given inputs/resources. In the case of manufacturing plants, for example, it would be worthy of emulating or learning from those companies that have achieved the highest profitability or plant productivity while implementing cost-effective corporate strategies, HR policies, technology adoption, etc. Inherent in this approach is the ability to consider both qualitative and quantitative differences in technology, capacity, maturity, competition, demographics, and so on, in the search for efficient (benchmark) units and peer groups.

The model is "politically neutral" in that it does not specify a position on whether or not plants should be located in a particular country or region. Economics teaches that friction (such 
as transaction costs) in the economy causes a sub-optimality. A production facility unnecessarily moved from one locale to another may increase transaction costs substantially.

Finally, it should be noted that the model presented is theoretical in nature and has not been directly tested. Extant literature on the topic, as well as observation of successful southeastern North Carolina companies as previously profiled seems to indicate that the practices outlined herein do have a direct effect on the success of firms who employ them. It should be further noted that factors external to the firm can have an impact on the "leave" or "stay" decision. The model presented here represents those factors completely within the control of the firm.

\section{References}

Beckett, Ron \& Hyland, Paul (2002). Learning to compete: the value of internal benchmarking. Benchmarking, 9(3) pg. 293.

Boyatzis, R. E. (1998). Transforming qualitative information: Thematic analysis and code development. Thousand Oaks, CA: Sage.

Charkiewicz, T. (2004). Efficiency is key to competing globally. Manufacturing Engineering, 132(4): pg. 88.

Coch, L. \& French, J. R. P. (1948). Overcoming resistance to change. Human relations, 1(4), p. 512-532.

Cohen, D. \& Prusak, L. (2001). In good company: How social capital makes organizations work. Boston: Harvard Business School Press.

Collins, J. (2001). Good to great: Why some companies make the leap . . and others don't. New York: Harper Business.

Davies, T. (2001). Enhancing competitiveness in the manufacturing sector: key opportunities provided by inter firm clustering. Competitiveness Review, 11(2), 4+.

Dhanaraj, C., Lyles, M. A., Steensma, H. K., \& Tihanyi, L. (2004). Managing tacit and explicit knowledge transfer in IJVs: The role of relational embeddedness and the impact on performance, Journal of International Business Studies. 35(5), 428+.

Eisen, P. (2003, December). Layoffs mask looming U.S. skills shortage. Pulp \& Paper, 77, 64.

Fry, L. W. (2003). Toward a theory of spiritual leadership. The Leadership Quarterly, 14(6), 693-728. 
Gunasekaran, A. \& Yusuf, Y. Y. (2002). Agile manufacturing: a taxonomy of strategic and technological imperatives. International Journal of Production Research, 40(6): pp. 13571385 .

Hemp, P. (2004). Presenteeism: at work- but out of it. Harvard Business Review, 82(10), 49.

Henry, Jenkins, Pinch \& Tallman (2004). Knowledge, clusters and competitive advantage. Academy of Management Review, 29(2), 258+.

HsiuJu R. Y. \& Chwen, S (2004). Aligning ERP implementation with competitive priorities of manufacturing firms: An exploratory study. International Journal of Production Economics. 92(3), 207-220.

Huberman, A. M., \& Miles, M. B. (2002). The qualitative researcher's companion ( ${ }^{\text {nd }}$ ed.). Sage Publications, Inc.

Kotter, J. (1996). Leading change. Boston: Harvard Business School Press

Kurlantzick, J. (2003, October). Made in America? Entrepreneur, 31, 72-75.

Lee, C. Y. (2003). Total manufacturing information system: a conceptual model of a strategic tool for competitive advantage. Integrated Manufacturing Systems, 14(2): pg. 114.

Luthans, F. \& Youssef, C. M. (2004). Human, social, and now positive psychological capital management: Investing in people for competitive advantage. Organizational Dynamics. $33(2), 143+$

Miles, M. B., and Huberman, A. M. (1984). Qualitative data analysis: A sourcebook of new methods. Beverly Hills: Sage Publications.

National Association of Manufacturers. (2001). The skills gap 2001: Manufacturers confront persistent skills shortages in an uncertain economy, Anderson: Center for Workforce Success.

Sahin, F. (2000). Manufacturing competitiveness: different systems to achieve the same results. Production and Inventory Management Journal, 41(1), 56+.

Strauss, A., \& Corbin, J. (1998). Basics of qualitative research: Techniques and procedures for developing grounded theory ( 2 nd ed). Thousand Oaks, CA: Sage.

Vokurka, R.J., \& Davis, R.A. (1996). Improving manufacturing competitiveness: A case study. Competitiveness Review, 6(1), 68-77. 
Yli-Renko, H., Autio, E. \& Sapienza, H. J. (2001). Social capital, knowledge acquisition, and knowledge exploitation in young technology-based firms. Strategic Management Journal, 22(6-7), 587 - 613.

\section{About the Authors}

Dr. Eric B. Dent is presently Dean and Professor, School of Business, University of North Carolina, Pembroke. He is committed to an interdisciplinary research agenda that has resulted in publications in behavioral science, complexity theory, systems science, education, consulting, history, communications, spirituality, organization development, and philosophy journals. Dr. Dent is a consultant to Fortune 500, government and non-profit organizations as well as an invited speaker to national audiences. He has received various awards for his scholarship, teaching, and service.

Robert D. Hughes is an MBA candidate at the University of North Carolina Pembroke in Pembroke, NC and expects to graduate in May of 2007. Mr. Hughes has a strong interest in manufacturing competitiveness, especially in southeastern North Carolina, as well as a belief that a strong manufacturing sector is vital to our nation's security and success in the world economy. 